Received: 03.08 .2020

Revised: 08.09.2020

Accepted: 16.10 .2020

DOI: $10.17804 / 2410-9908.2020 .5 .058-069$

\title{
THE INFLUENCE OF THE CONSTRUCTIVE FEATURES OF THE PLASMOTRON ON THE QUALITY OF THE CUT DURING AIR-PLASMA CUTTING OF SHEET METALS
}

\author{
S. V. Anakhov ${ }^{1, a)}$, B. N. Guzanov ${ }^{1, b)}$, N. B. Pugacheva, ${ }^{2, c)}$, \\ T. M. Bykova $\left.{ }^{2,}\right)^{*}$, and A. V. Matushkin ${ }^{3, e)}$ \\ ${ }^{1}$ Russian State Vocational Pedagogical University, \\ 11 Mashinostroiteley St., Ekaterinburg, 620012, Russian Federation \\ ${ }^{2}$ Institute of Engineering Science, Ural Branch of the Russian Academy of Sciences, \\ 34 Komsomolskaya St., Ekaterinburg, 620049, Russian Federation \\ ${ }^{3}$ B.N. Yeltsin Ural Federal University, \\ 19 Mira St., Ekaterinburg, 620002, Russian Federation

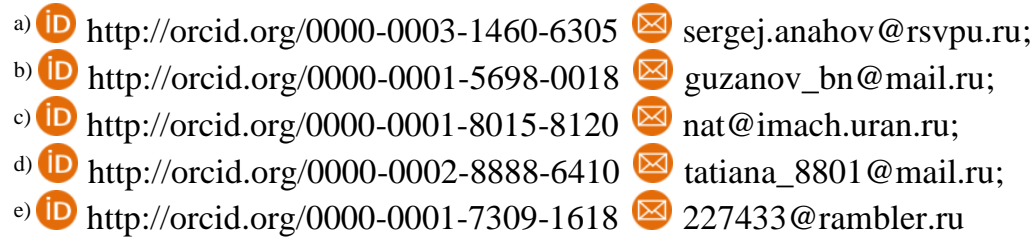 \\ *Corresponding author. E-mail: tatiana_8801@mail.ru
} Address for correspondence: 34 Komsomolskaya St., Ekaterinburg, 620049, Russian Federation Tel.: +7 (343) 36230 43; fax: +7 (343) 3745330

The features of structure formation in the heat-affected zone, which are formed in the process of plasma cutting of $10 \mathrm{~mm}$ and $36 \mathrm{~mm}$ thick St3ps steel sheets, are presented. Cutting of thick steel is accompanied by high carburization, increasing hardness of the surface layer, and increasing surface roughness parameters. The research results allow us to conclude that the developed PMVR9.1 plasmatron makes it possible to perform sufficiently high-quality cutting of sheet steel with a thickness of up to $40 \mathrm{~mm}$ and more. However, butt welding after plasma cutting without preliminary machining can be performed for a steel thickness of $10 \mathrm{~mm}$.

Keywords: steel, plasmatron, plasma cutting, microstructure, roughness, microhardness.

\section{Acknowledgment}

This work was supported by the state assignment of the Ministry of Education and Science of the Russian Federation for 2018-2019, No. 13.10317.2018/11.12 (Reg. No. R\&D AAAA-A18118110790009-3).

\section{References}

1. Kaidalov A.A. Sovremennye tekhnologii termicheskoi i distantsionnoi rezki konstruktsionnykh materialov [Modern Technologies of Thermal and Remote Cutting of Constructional Materials]. Kiev, Ekotekhnologiya Publ., 2007, 456 p. (In Russian).

2. Lashchenko G.I. Plazmennaia rezka metallov $i$ splavov [Plasma Cutting of Metals and Alloys]. Kiev, Ekotekhnologiya, 2003, 64 p. (In Russian).

3. $\quad$ Koroteev A.C., Mironov V.M., Svirchuk Yu.S. Plazmotrony. Konstryktsii, kharakteristiki, raschet [Plasmatrons. Designs, characteristics, calculation]. Moscow, Mashinostroenie Publ, 1993, 296 p. (In Russian). 
4. Zhukov M.F., An'shakov A.S. Osnovy rascheta plazmotronov lineinoi skhemy [Bases of Calculation of Plasmatrons of the Linear Scheme]. Novosibirsk, Institut teplofiziki Sibirskogo otdeleniia Rossiiskoi akademii nauk SSSR, 1979, 146 p. (In Russian).

5. Donskoi A.V., Klubnikin V.S. Elektroplazmennye protsessy i ustanovki v mashinostroenii [Electroplasma Processes and Installations in Mechanical Engineering]. Leningrad, Mashinostroenie Publ., 1979, 221 p. (In Russian).

6. Anakhov S.V. and Pykin Yu.A. Plazmotrony: problema akusticheskoi bezopasnosti. Teplofizicheskie i gazodinamicheskie printsipy proektirovaniya maloshumnykh plazmotronov [Plasmatrons: The Problem of Acoustic Safety. Thermal Physic and Gas-Dynamic Principles of Design of a Low-Noise Plasmatrons]. Yekaterinburg, Ural. Otd., Ross. Akad. Nauk, 2012. (In Russian).

7. Chieu Kuang Fi. Issledovanie effektivnosti tekhnologii uzkostruinoi plazmennoi rezki metallov [Investigation of the efficiency of narrow jet plasma technology for metal cutting]. PhD. Thesises, Saint-Petersburg, 2008, 143 p. (In Russian).

8. Shalimov M.P., Anakhov S.V., Pykin Iu.A., Matushkin A.V., Matushkina I.Yu. Estimation of efficiency of gas vortex stabilization in metal cutting plasma torches. Svarka i Diagnostika, 2018, no. 2, pp. 57-61. (In Russian).

9. Anakhov S.V. Printsipy i metody proektirovaniia $v$ elektroplazmennykh i svarochnykh tekhnologiiakh: ucheb. posobie [The principles and design methods in electroplasma and welding technologies]. Ekaterinburg, Izd-vo Ros. Gos. Prof-ped. Un-ta Publ., 2018, 165 p. (In Russian).

10. Anakhov S.V., Pykin Yu.A., Matushkin A.V. Improving the efficiency of the gas-vortex stabilization system in plasmatrons for high-precisioncutting of metals. Svarochnoe Proizvodstvo, 2019, no. 4, pp. 27-30. (In Russian).

11. Anakhov S.V., Guzanov B.N., Matushkin A.V., Pugacheva N.B., Pykin Y.A. Influence of plasma torch design on cutting quality during precision air-plasma cutting of metal. Izvestiya. Ferrous Metallurgy, 2020, vol. 63 (2), pp. 155-162. (In Russian). DOI: 10.17073/0368-0797-20202-155-162.

12. GOST 8233-56. Steel. Microstructure standards. Moscow, IPK Izdatelstvo Standartov Publ., 2004. (In Russian). 
Подана в журнал: 03.08.2020

УДК 620.18:621.791; 53.06:09,67.08

DOI: $10.17804 / 2410-9908.2020 .5 .058-069$

\title{
ВЛИЯНИЕ КОНСТРУКТИВНЫХ ОСОБЕННОСТЕЙ ПЛАЗМОТРОНА НА КАЧЕСТВО РЕЗА ПРИ ВОЗДУШНО-ПЛАЗМЕННОМ РАСКРОЕ ЛИСТОВЫХ МЕТАЛЛОВ
}

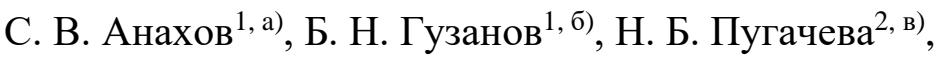 \\ Т. М. Быкова ${ }^{2, \text { г)* , А. В. Матушкин }}{ }^{3, \text { д) }}$ \\ ${ }^{1}$ Российский государственный профессионально-педагогический университет, \\ 11, ул. Машиностроителей, г. Екатеринбург, 620012, Российская Федерация \\ ${ }^{2}$ Институт машиноведения УрО РАН, \\ 34, ул. Комсомольская, г. Екатеринбург, 620049, Российская Федераџия \\ ${ }^{3}$ Уральский федеральный университет имени первого Президента России Б.Н. Ельиина, \\ 19, ул. Мира, г. Екатеринбург, 620002, Российская Федерация \\ a) iD http://orcid.org/0000-0003-1460-6305 \\ б) (iD http://orcid.org/0000-0001-5698-0018 \\ в) (iD http://orcid.org/0000-0001-8015-8120 \\ г) (iD http://orcid.org/0000-0002-8888-6410 \\ д) (iD http://orcid.org/0000-0001-7309-1618
sergej.anahov@rsvpu.ru; guzanov_bn@mail.ru; nat@imach.uran.ru; tatiana_8801@mail.ru; 227433@rambler.ru \\ *Ответственный автор. Электронная почта: tatiana_8801@mail.ru \\ Адрес для переписки: ул. Комсомольская, 34, г. Екатеринбург, Российская Федерация \\ Тел.: +7 (343) 362-30-43, факс: +7 (343) 374-53-30
}

Представлены особенности образования структуры в зоне термического влияния, формирующиеся в процессе плазменной резки листов стали Ст3пс толщиной 10 мм и 36 мм. При резке стали большой толщины наблюдается повышенное науглероживание, рост твердости приповерхностного слоя и увеличение параметров шероховатости поверхности. Результаты исследований позволяют сделать вывод о том, что разработанный плазмотрон ПМВР-9.1 позволяет произвести достаточно качественный раскрой листовой стали толщиной до 40 мм и более. Однако стыковую сварку после плазменной резки без предварительной механической обработки можно производить при толщине стали 10 мм.

Ключевые слова: сталь, плазмотрон, плазменная резка, микроструктура, шероховатость, микротвердость.

\section{1. Введение}

Воздушно-плазменная резка металлов - одна из наиболее широко используемых технологий в металлургических и машиностроительных производствах для резки металлопроката и раскроя листовых материалов. При проектировании металлорежущих плазмотронов [1], как правило, опираются на такие критерии как производительность, качество реза и надежность их работы [2]. Высокие значения данных параметров в свою очередь зависят от эффективности системы газовихревой стабилизации (ГВС) [3, 4], обеспечивающей высокую степень тепловложения и кинетические свойства плазменной дуги (струи), надежность работы катодного и соплового узлов плазмотрона [5]. Применяемый в современных плазмотронах для резки металлов газовихревой способ стабилизации основан на тангенциальной подаче плазмообразующего газа (ПОГ) в сопловой узел и обжатии плазменной дуги (струи) как самим соплом, так и вихревым потоком стабилизирующего газа в цилиндрическом канале сопла (или на выходе из сопла вторичным потоком стабилизирующего газа в технологии уз- 
коструйной плазмы) [6, 7]. Формирование тангенциально закрученного потока газа происходит в вихревых камерах (завихрителях), количество, конструкция и расположение которых в плазмотроне существенным образом влияет на эффективность резки металлов [8].

За последние годы авторами была разработана комплексная система анализа организации течения потока плазмообразующего газа по каналам газовоздушного тракта (ГВТ) плазмотрона и созданы новые системы стабилизации дугового разряда металлорежущих плазмотронов постоянного тока для повышения их технологических показателей. Необходимость разработки новых плазмотронов обусловлена тем, что среди разработок отечественного электроплазменного оборудования практически отсутствуют инструментальные плазмотроны для прецизионной резки стальных листов при толщинах проката до 40 мм, обеспечивающие повышенную точность и качество реза кромок, высокую материальную и энергетическую эффективность. Это становится наиболее важным, так как в настоящее время на рынке присутствует качественная продукция только зарубежных производителей (Hypertherm, Kjellberg, MesserGreisheim и др.), что в условиях санкционной политики западных стран требует безусловного импортозамещения в этой весьма ответственной и быстро развивающейся технологической составляющей заготовительного производства [9].

Комплексная система анализа течения потока ПОГ включает методы численного моделирования газодинамических и теплофизических параметров процессов плазмообразования в плазмотроне (рис. 1). Подобный анализ проводился в приложении FlowWorks программной среды SolidWorks в рамках исследования широкого ряда отечественных и импортных плазмотронов постоянного тока. Результаты исследования выявили конструктивные недостатки большинства плазмотронов с точки зрения эффективности работы их систем ГВС и позволили разработать новые комплексные системы ГВС дуговых плазмотронов с более равномерным распределением по сечению ГВТ потока плазмообразующего газа.

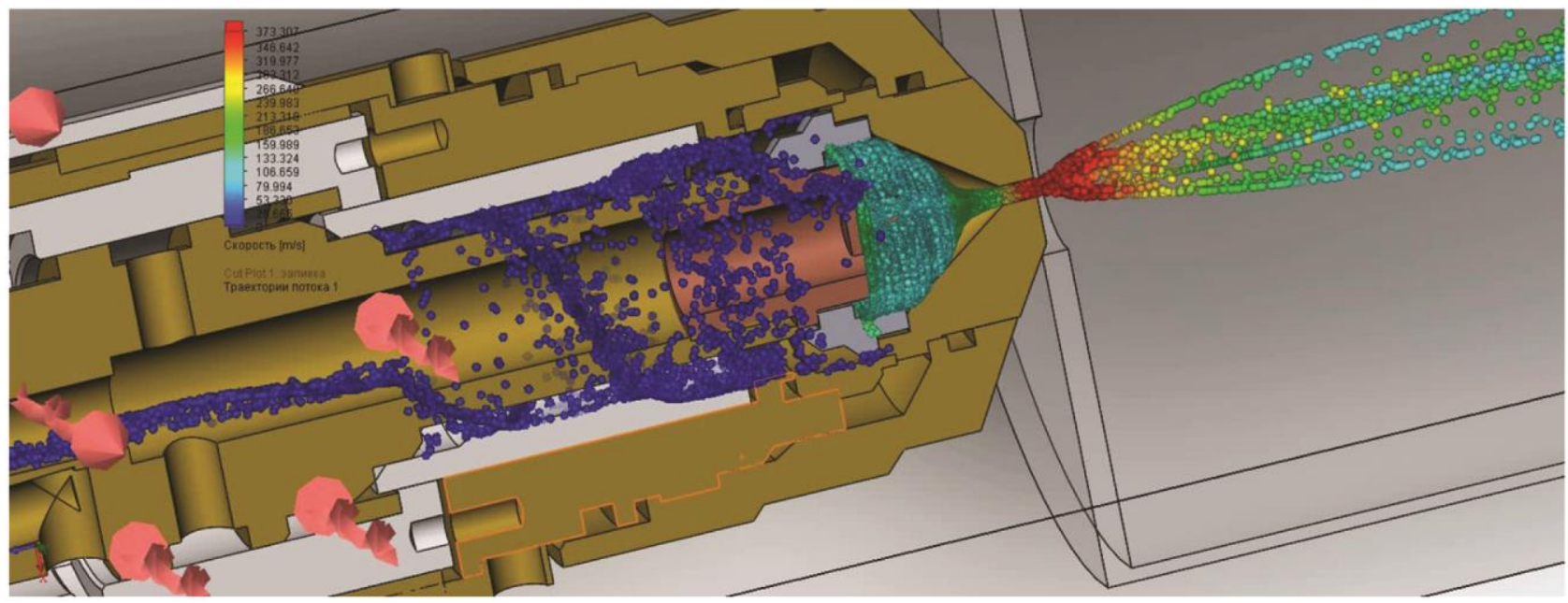

Рис. 1. Моделирование газодинамических характеристик потока плазмообразующего газа по газовоздушному тракту одноконтурного плазмотрона

(схема без предварительного завихрителя)

Новые системы ГВС были использованы для создания опытно-промышленных и опытных моделей однопоточных плазмотронов для прецизионной резки металлов средних и больших толщин серии ПМВР-5, а также двухпоточных плазмотронов серии ПМВР-9 для высокоточной узкоструйной резки металлов малых и средних толщин. В частности, в камере расширения ГВТ плазмотрона ПМВР-5.1 (рис. 2) была применена система газодинамических фильтров в виде сплошных и перфорированных стенок, а также оптимизирована геометрия отдельных участков ГВТ. В плазмотроне ПМВР-5.2 (рис. 3 a) была предложена система ГВС с симметричной подачей ПОГ в камеру расширения и двумя завихрителями в системе ГВС 
(рис. 3 б): 1-я расширительная камера (камера смешения) - предварительный (формирующий) завихритель - 2-я расширительная камера - основной (стабилизирующий) завихритель. Размеры и расположение элементов системы ГВС в плазмотроне ПМВР-5.2 были также определены в рамках оптимизационных процедур по критериям эффективности ГВС. В целях последующего совершенствования систем ГВС в однопоточном плазмотроне ПМВР-5.3 дополнительно применен встроенный ступенчатый газодинамический фильтр с модернизированным завихрителем, обеспечивающим повышение радиальной составляющей скорости ПОГ в сопловом узле (рис. 4). В результате плазмотрон ПМВР-5.3 показал повышенную (на 40 \% по сравнению с базовым плазмотроном типа ПМВР) производительность работы на токах до 200 А и качество реза металлов толщиной до 40 мм [10, 11].

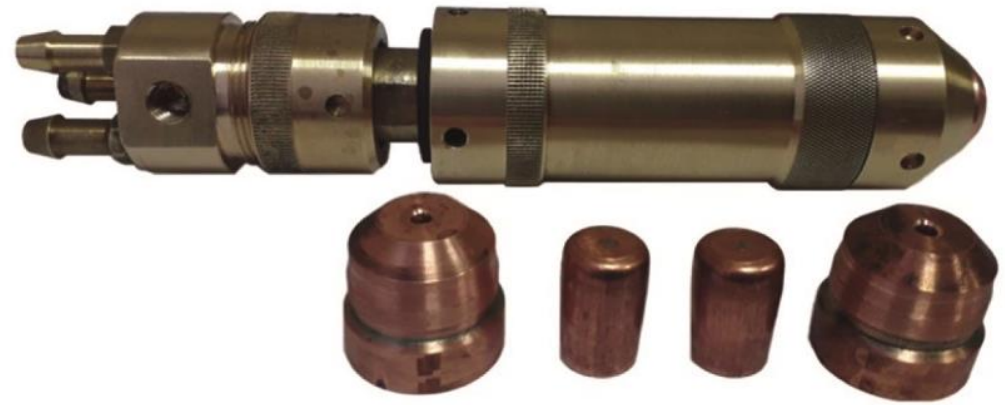

Рис. 2. Опытно-промышленная модель плазмотрона ПМВР-5.1 с элементами соплового узла

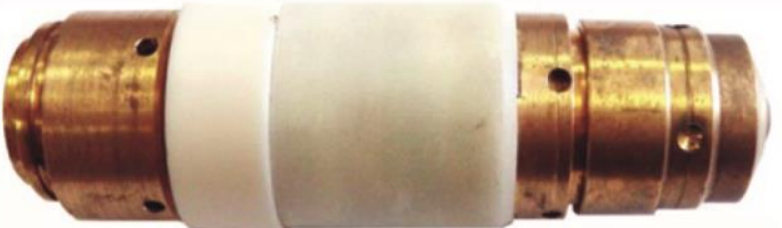

$a$

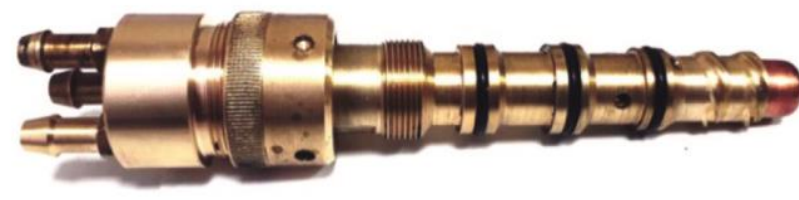

б

Рис. 3. Плазмотрон ПМВР-5.2: $a$ - опытно-промышленная модель; $\sigma$ - элементы конструкции (ГВТ с двумя завихрителями и хвостовая часть)

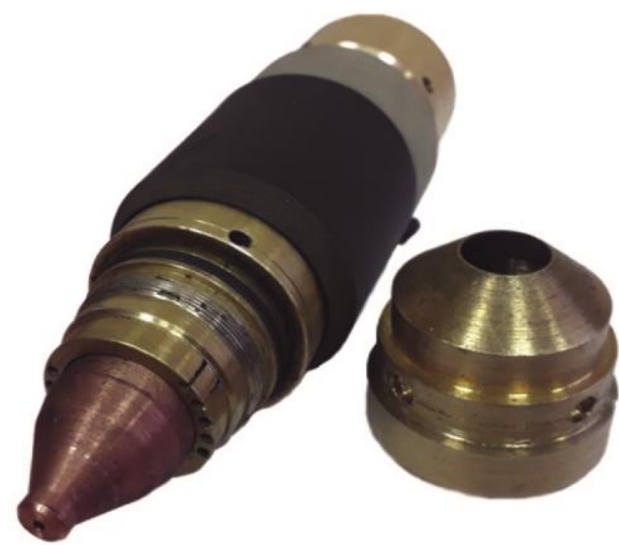

Рис. 4. Опытная модель плазмотрона ПМВР-5.3

На базе решений, полученных при проектировании ГВТ однопоточных плазмотронов, был разработан двухпоточный плазмотрон ПМВР-9.1, работающий по высокотехнологичной схеме «узкоструйной плазмы» (рис. 5). В основе технологии лежит применение двухпоточного принципа стабилизации - двойного вихревого обжатия плазменной дуги за счет распределения плазмообразующего газа по двум контурам на 2 потока (формирующего струю 
и стабилизирующего дугу). Применение подобного плазмотрона позволило решить многие проблемы плазменной резки за счет существенного снижения ширины реза, улучшения его качества, повышения эффективности, материало- и энергоемкости процесса, а также обеспечить систематическое импортозамещение расходуемого оборудования для установок энергетической резки металлических материалов.

Опытно-промышленная апробация плазмотрона ПМВР-9.1 показали, что в отличие от однопоточных плазмотронов серии ПМВР-5, обеспечивающих прецизионную резку металлов средних толщин, он обеспечивает повышенное (сравнимое с лазерным) качество реза металлов толщиной до 20 мм за счет конструктивного и технологического изменения системы ГВС плазменной дуги.

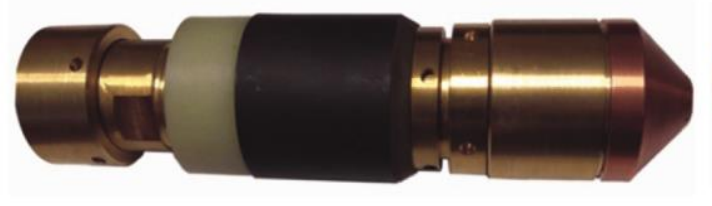

$a$

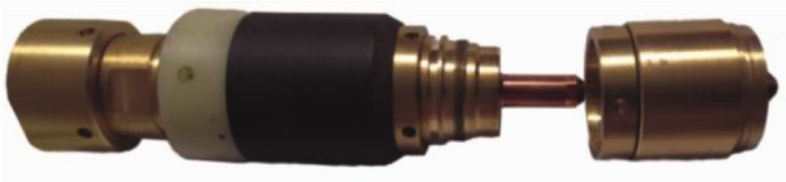

$\sigma$

Рис. 5. Опытная модель плазмотрона ПМВР-9.1: $a$ - в сборе; $\sigma$ - элементы конструкции

Примененные методы анализа с учетом известных ранее и созданных в процессе исследования новых критериев и принципов легли в основу новой комплексной методики проектирования металлорежущих плазмотронов по газодинамическим, теплофизическим и акустическим критериям $[6,9,10]$. Методика утверждена в Уральском институте сварки и позволяет разрабатывать новые конструктивные схемы и оценивать эффективность проектирования систем стабилизации дугового разряда плазмотронов. В качестве особых методических рекомендаций можно отметить способы оценки влияния конструктивных особенностей систем ГВС на кинематические параметры плазменной струи. С применением данных способов было показано, что применение новых комплексных систем ГВС в плазмотронах ПМВР5.3 и ПМВР-9.1 позволило улучшить газодинамические и энергетические параметры плазменной дуги (струи) (рис. 6). Разработанная методика позволяет также произвести оценку технологических возможностей плазмотронов при резке металлов различных толщин, а также ряд параметров их безопасного применения.

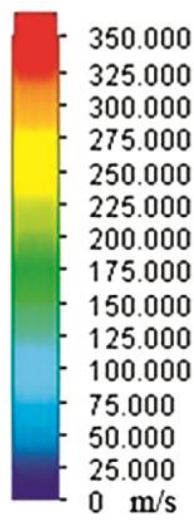

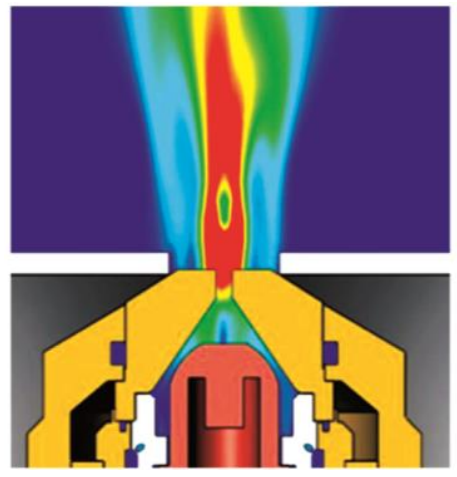

ПМВР-5.3 с серийным завихрителем

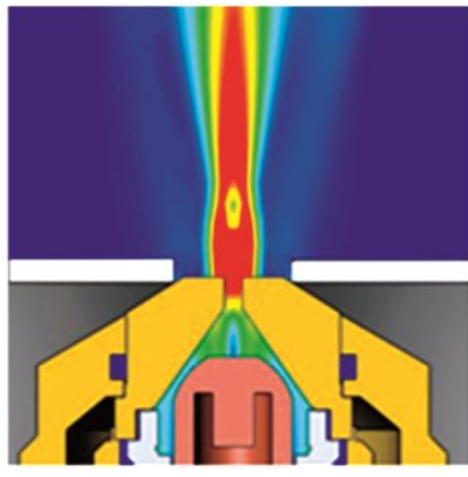

ПМВР-5.3

с модернизированным завихрителем

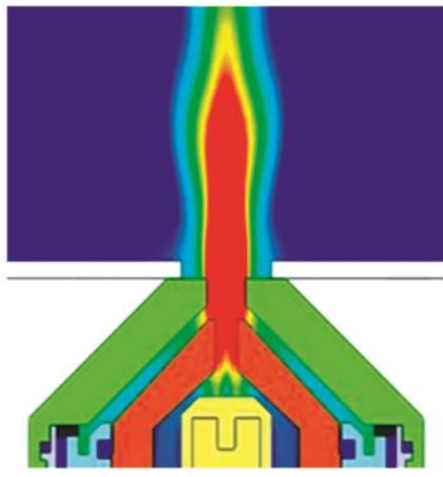

ПМВР-9.1

двойное сопло с вихревым обжатием

Рис. 6. Численное моделирование кинематических параметров плазменной струи в плазмотронах ПМВР-5.3 и ПМВР-9.1 
Комплексная методика проектирования включает и экспериментальную верификацию результатов численного моделирования процессов, характерных для технологии плазменной резки. Экспериментальные результаты, полученные в ходе исследований, проведенных совместно с Институтом машиноведения УрО РАН, подтвердили эффективность применения новых методов ГВС. Например, резка металлов плазмотронами типа ПМВР-9.1 позволяет получать прецизионные резы, соответствующие 1 и 2-м классам качества по ГОСТ 14792-80 на углеродистых и низколегированных сталях средних толщин. Кроме того, была показана возможность применения таких плазмотронов для прецизионной резки металлов и последующей их сварки без дополнительной механической обработки кромки реза.

\section{2. Материалы и методы исследования}

С использованием указанного плазмотрона было выполнено исследование структурообразования ЗТВ при узкоструйной воздушно-плазменной резке листа углеродистой стали Ст3пс при следующих параметрах работы плазмотрона: ток резки - 120 А; напряжение резки $\sim 180 \mathrm{~B}$; давление ПОГ 4,5 атм.; диаметр сопла - 1,9 мм; вылет плазмотрона - 6-7 мм. Скорость резки была выбрана в зависимости от толщины листа стали и соответствовала 1,5 м/мин при толщине 10 мм и 0,3 м/мин - при толщине 36 мм.

Структурные исследования выполнены на микроскопе NEOPHOT-21 при увеличениях от 100 до 1000 крат. Определение дисперсности пластинчатого перлита и соотношение фаз феррита и перлита в зоне термического влияния в кромке реза было выполнено в соответствии с межгосударственным стандартом ГОСТ 8233-56 [12] на специально вырезанных темплетах при увеличении 1000 крат (рис. $8 a$ и б). Количественная характеристика основных элементов микроструктуры была произведена на основании сопоставления структуры с эталонами соответствующих шкал стандарта.

Химический состав листовой стали определяли спектральным методом на приборе SPECTROMAX и усредняли по прожигам в нескольких участках площадью 8 мм ${ }^{2}$ на поверхности сечения образцов. Для определения распределения химических элементов на поверхности реза был проведен рентгеноспектральный анализ при увеличении 2000 крат на растровом электронном микроскопе TESCAN VEGA IIXMU, оснащенном системами энергодисперсионного микроанализа INCA ENERGY 450 с АДД детектором OXFORD и программным обеспечением INCA. Исследование рельефа поверхности резов выполнили с помощью оптического интерферометра Vеeсо NT-1100. Значение твердости определены на приборе LEICA с программным обеспечением Materials Workstation при нагрузке 25 г на верхней и нижней кромках реза.

\section{3. Обсуждение результатов}

Анализ микроструктур позволяет заключить, что при изменении условий резки в зависимости от толщины разрезаемого листа обнаружены значительные различия в структурообразовании зоны термического влияния (ЗТВ) в исследуемых образцах (рис. 7 и 8). На рис. 7, $a$ и $б$ представлена в сравнении микроструктура внешней зоны плазменной резки исследованных образцов при увеличении 100 крат в зависимости от толщины листа, а в табл. 1 дано описание структуры образцов в каждой зоне.

Определение дисперсности пластинчатого перлита и соотношение фаз феррита и перлита в зоне термического влияния в кромке реза было выполнено в соответствии с межгосударственным стандартом ГОСТ 8233-56 [12] на специально вырезанных темплетах при увеличении 1000 крат (рис. 8 а и б).

Количественная характеристика основных элементов микроструктуры была произведена на основании сопоставления структуры с эталонами соответствующих шкал стандарта. 
Анализ микроструктур позволяет заключить, что при изменении условий резки в зависимости от толщины разрезаемого листа обнаружены значительные различия в структурообразовании зоны термического влияния (3О+П3) в исследуемых образцах.

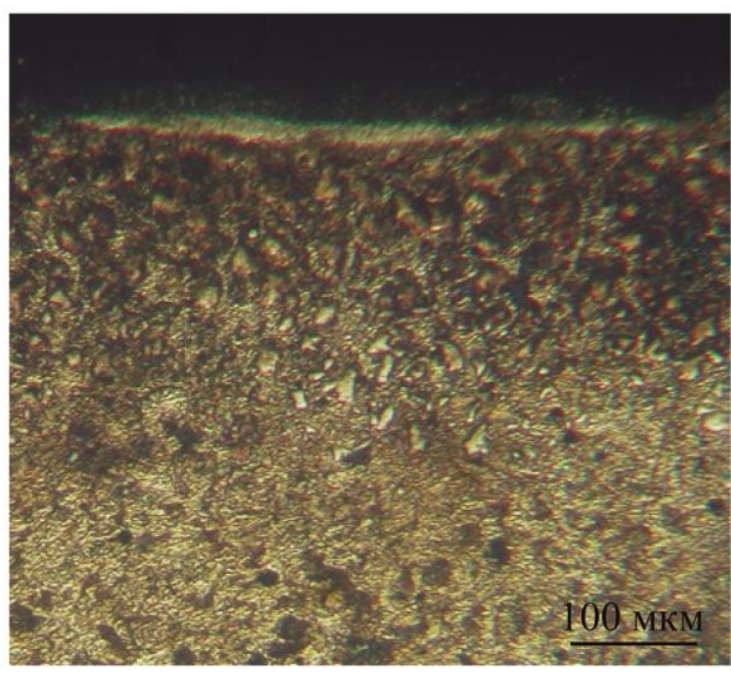

$a$

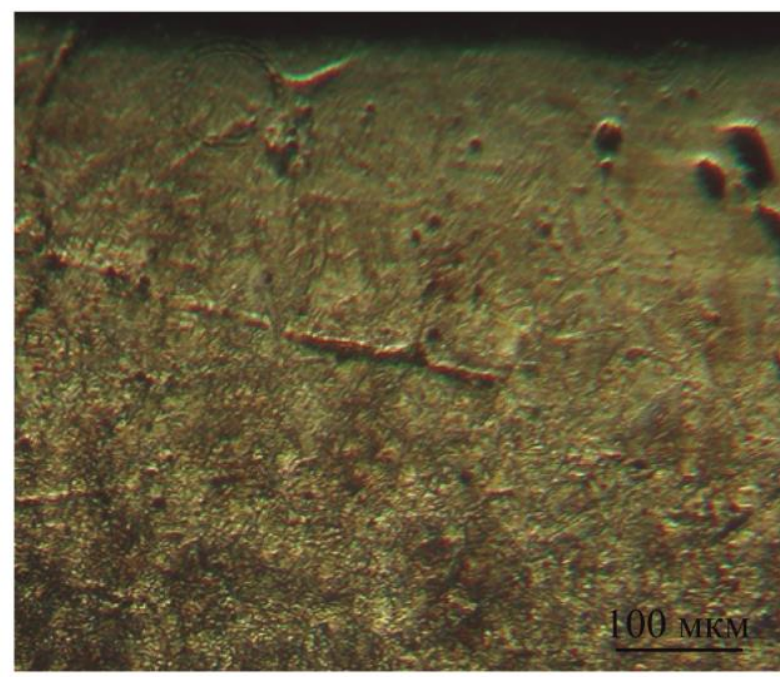

$\sigma$

Рис. 7. Микроструктура приповерхностных слоев исследуемой стали после плазменной резки: $a$ - толщина листа 10 мм; $\sigma$ - толщина листа 36 мм

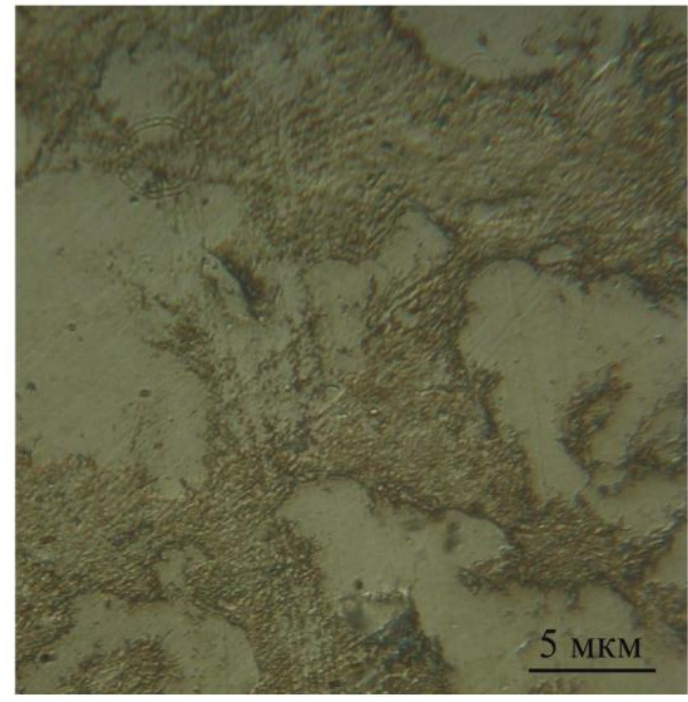

$a$

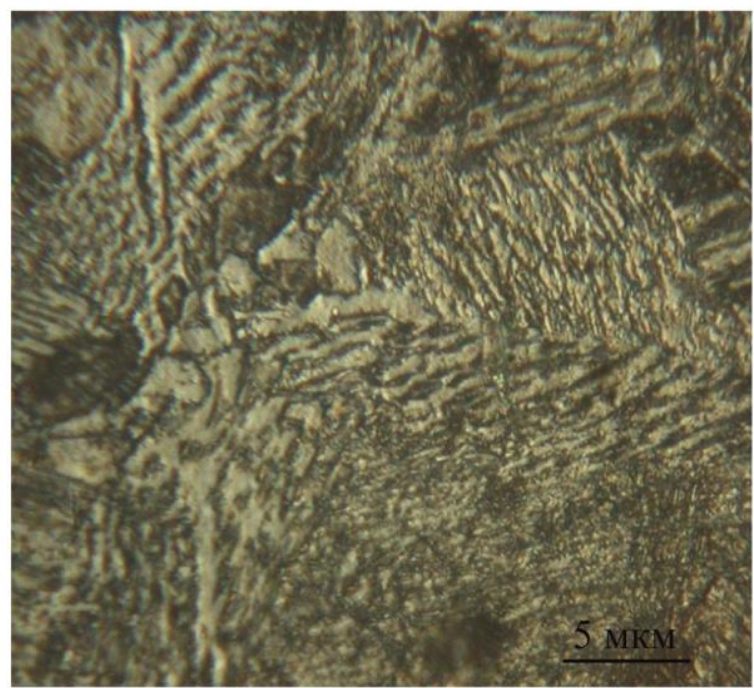

6

Рис. 8. Микроструктура зоны термического влияния исследуемой стали после плазменной резки: $a$ - толщина листа 10 мм; $\sigma$ - толщина листа 36 мм

Так, с уменьшением скорости реза практически в 3 раза увеличилась толщина ЗТВ при прочих неизменных параметрах работы плазмотрона. На поверхности реза в обоих случаях формируется не травящийся белый слой бесструктурного мартенсита, а в ЗТВ сформировались перлито-ферритные структуры с разными количественными соотношениями фаз и отличающейся степенью дисперсности (табл. 1). При скорости резания 1,5 м/мин в тонкой пластине в ЗТВ за счет перекристаллизации в условиях интенсивного теплоотвода образовалась мелкозернистая структура сорбитообразного перлита 1-го балла, в то время как в толстой пластине при скорости резания 0,3 м/мин сформировалась структура укрупненного зер- 
на среднепластинчатого перлита 7-го балла (рис. 8). В переходных зонах исследуемых образцов резко возросло количество перлита в перлито-ферритной структуре по сравнению с исходным соотношением в основе стали (табл. 1).

Таблица 1 - Описание структуры образца в каждой зоне

\begin{tabular}{|c|c|c|c|}
\hline $\begin{array}{l}\text { Толщина } \\
\text { образца, } \\
\text { мм }\end{array}$ & Зона & $\begin{array}{c}\text { Толщина } \\
\text { зоны, мкм }\end{array}$ & Структура \\
\hline \multirow{4}{*}{10} & Край реза & 25 & Бесструктурный мартенсит \\
\hline & $\begin{array}{l}\text { Внешняя часть ЗТВ } \\
\left(3 \mathrm{~TB}_{1}\right)\end{array}$ & 175 & $\begin{array}{l}\text { Сорбитообразный перлит, 1-й балл, } \\
\text { межпластинчатое расстояние менее } \\
0,20 \text { мкм }\end{array}$ \\
\hline & $\begin{array}{l}\text { Переходная зона } \\
\left(\text { (ТВ }_{2}\right)\end{array}$ & 200 & $\begin{array}{l}\text { Перлито-ферритная структура } \\
\text { с соотношением п/ф = 85/15, 3-й балл }\end{array}$ \\
\hline & Основа стали & $>400$ & $\begin{array}{l}\text { Перлито-ферритная структура с соотно- } \\
\text { шением п } / \phi=20 / 80,8 \text {-й балл }\end{array}$ \\
\hline \multirow{4}{*}{36} & Край реза & 10 & Бесструктурный мартенсит \\
\hline & Внешняя часть $3 \mathrm{~TB}_{1}$ & 390 & $\begin{array}{l}\text { Среднепластинчатый перлит, 7-й балл, } \\
\text { межпластинчатое расстояние менее } \\
1,20 \text { мкм }\end{array}$ \\
\hline & $\begin{array}{l}\text { Переходная зона } \\
\text { ЗТВ }_{2}\end{array}$ & 800 & $\begin{array}{l}\text { Перлито-ферритная структура } \\
\text { с соотношением п/ } \phi=95 / 5,2 \text {-й балл }\end{array}$ \\
\hline & Основа стали & $>1200$ & $\begin{array}{l}\text { Перлито-ферритная структура } \\
\text { с соотношением п/ } \phi=20 / 80\end{array}$ \\
\hline
\end{tabular}

Подобные особенности структурообразования определяются главным образом различиями скоростей охлаждения поверхностных слоев углеродистой стали при отличающихся режимах резки. Влияние оказало и перераспределение легирующих элементов и углерода в разделочных швах в процессе энергетической обработки. Микрорентгеноспектральный анализ показал (рис. 9), что в результате диффузионного перераспределения углерода повысилась его концентрация в зоне реза. Из приведенных графиков распределения видно, что повышение концентрации углерода в различных зонах реза носит нерегулярный характер. Максимальное повышение наблюдается в зоне оплавления вблизи кромки реза, затем в зоне оплавления несколько снижается и к концу переходной зоны количество углерода выравнивается в соответствии с химическим составом основы. Все это в полной мере отражает характер образовавшихся структур в различных зонах реза по мере удаления от кромки.

Особо следует отметить, что степень науглероживания при резке толстой пластины с малой скоростью оказалась значительно выше и достигла значений в кромке реза 0,76 мас. \% C, в то время как в тонкой пластине при высокой скорости реза не превысила 0,25 мас. \% С, при усредненной концентрации углерода в основе 0,14 мас. \% С. При этом в зоне оплавления в результате сильной энергетической обработки в зоне реза толстого листа за счет выгорания значительно снизилась массовая доля марганца и кремния, что в тонком листе по всей толщине практически не наблюдалось.

Изменение концентрации углерода в поверхностных слоях привело к измельчению перлито-ферритная структуры и повышению твердости приповерхностных слоев стали в зоне плазменной резки (рис. 10). В наиболее явной форме это заметно для малой скорости реза, при которой в поверхности за счет диффузионных процессов сформировалось высокоуглеродистое состояние стали. 


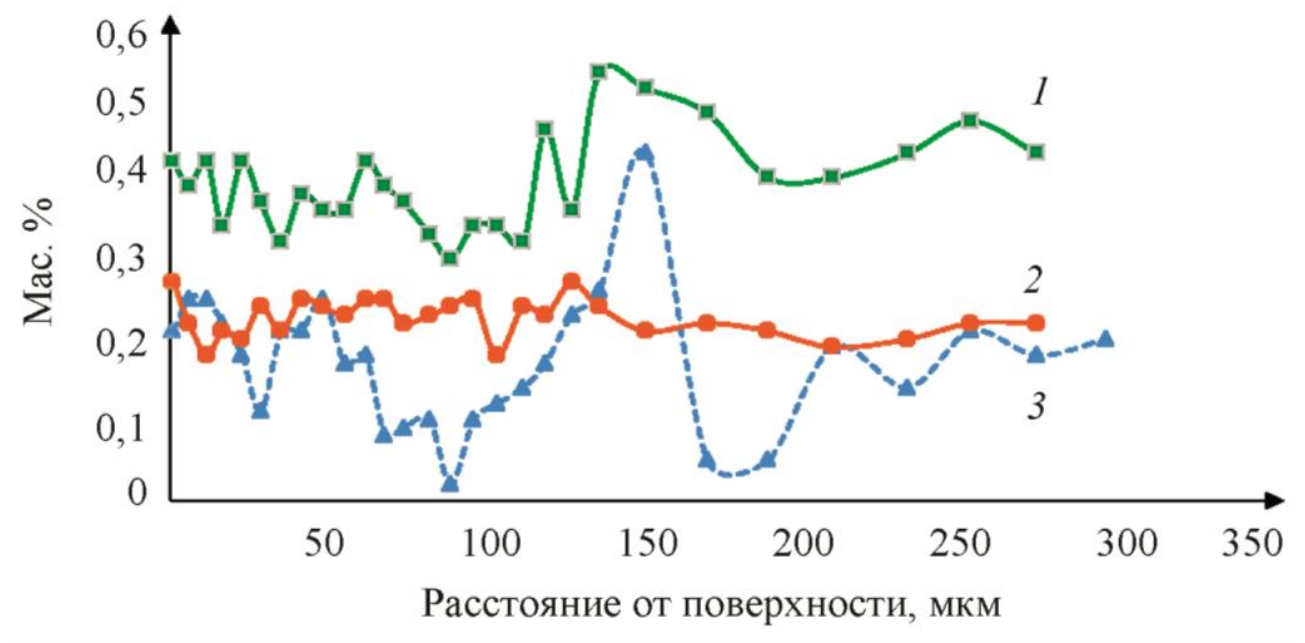

$a$

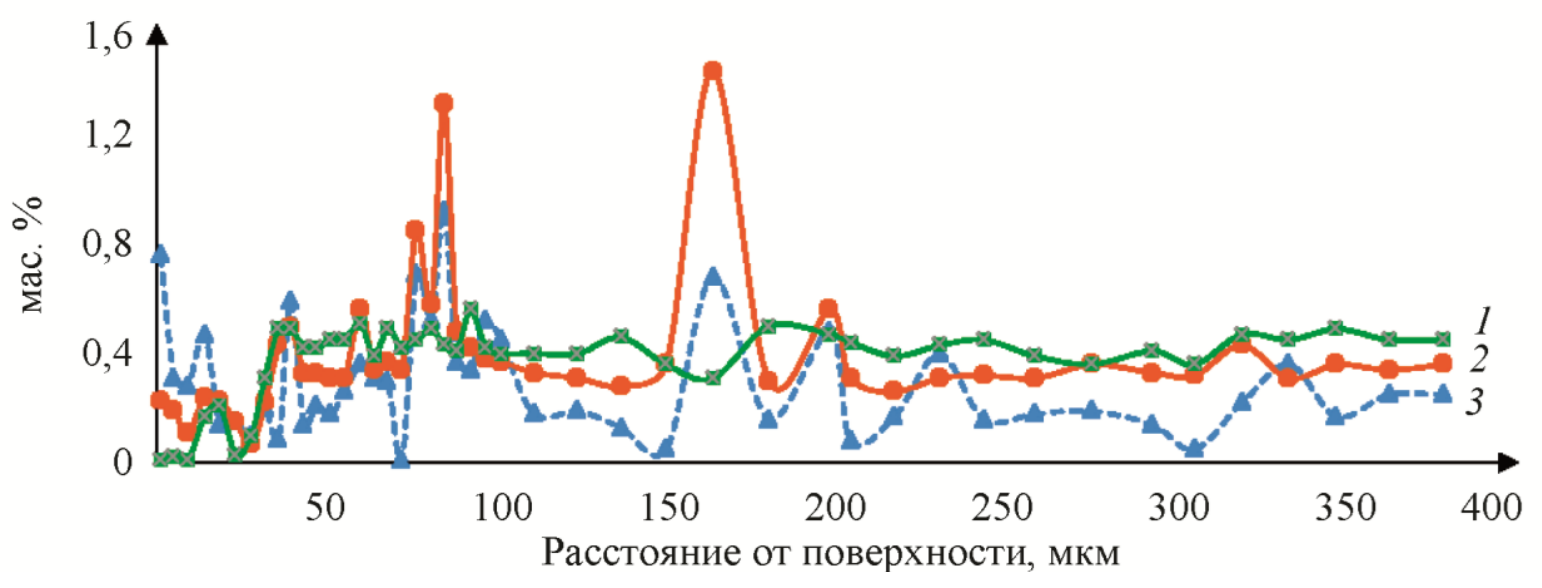

б

Рис. 9. Распределение легирующих элементов исследуемой стали в зоне термического влияния плазменной резки: $a$ - толщина листа 10 мм; $\sigma$ - толщина листа 36 мм; $1-\mathrm{Mn} ; 2-\mathrm{Si} ; 3-\mathrm{C}$

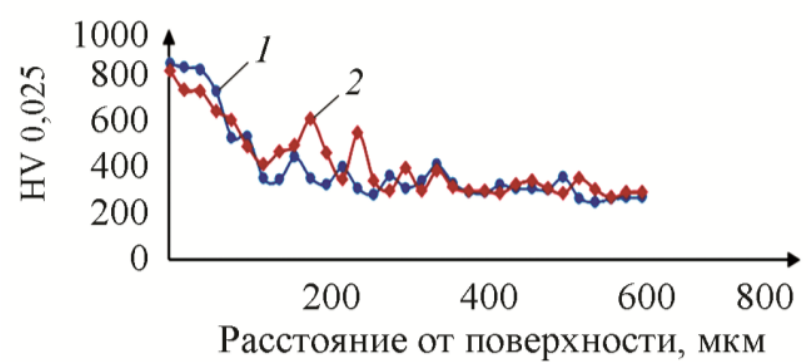

$a$

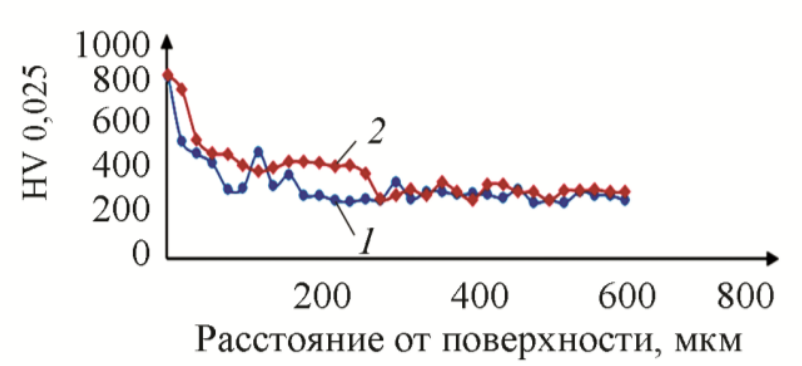

6

Рис. 10. Графики распределения твердости в образцах: $a$ - толщина листа 10 мм; $\sigma$ - толщина листа 36 мм; 1 - нижняя кромка; 2 - верхняя кромка

Весьма важно отметить практически одинаковый характер распределения твердости на верхней и нижней кромках реза исследованных образцов, что обусловлено конструктивными особенностями разработанного узкоструйного плазмотрона. 
Большое значение при оценке качества плазменной резки отводится изучению шероховатости поверхности по критериям микрогеометрии рельефа линии реза. Результаты исследования представлены на рис. 11 и приведены в табл. 2.
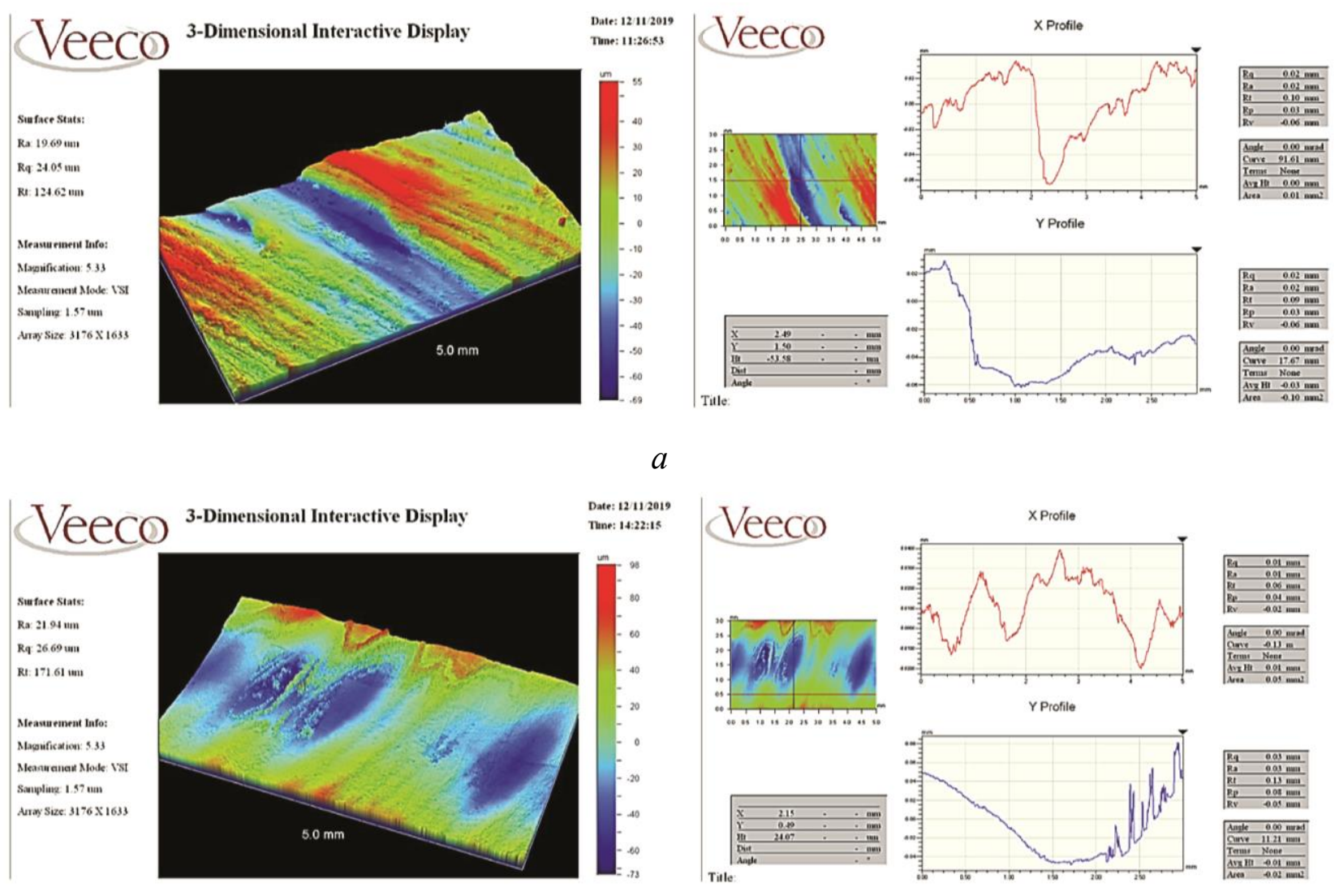

$\sigma$

Рис. 11. Анализ рельефа поверхности исследованных образцов: $a$ - толщина листа 10 мм; $б$ - толщина листа 36 мм

Таблица 2 - Результаты исследования рельефа поверхности

\begin{tabular}{|c|c|c|c|}
\hline $\begin{array}{c}\text { Толщина листа, } \\
\text { мм }\end{array}$ & $\begin{array}{c}\text { Средняя } \\
\text { шероховатость } \mathrm{R}_{\mathrm{a}}, \\
\text { мкм }\end{array}$ & $\begin{array}{c}\text { Средняя квадратичная } \\
\text { шероховатость } \mathrm{R}_{\mathrm{q}}, \\
\text { мкм }\end{array}$ & $\begin{array}{c}\text { Максимальная } \\
\text { высота поверхности } \mathrm{R}_{\mathrm{t}}, \\
\text { мкм }\end{array}$ \\
\hline 10 & 19,69 & 24,05 & 124,62 \\
\hline 36 & 21,94 & 26,69 & 171,61 \\
\hline
\end{tabular}

Видно, что по всем оцениваемым показателям качество поверхности реза толстого листа при медленной скорости перемещения плазмотрона оказалось несколько хуже, чем при резке тонкого листа. Особенно это заметно по величине максимальной высоты поверхности (вертикальное расстояние между самой высокой и самой низкой точкой рельефа), что говорит о большей волнистости линии реза в этом случае.

\section{4. Выводы}

Таким образом, по результатам выполненных исследований можно заключить, что разработанный плазмотрон ПМВР-9.1 по своим техническим возможностям за счет использования новой системы ГВС с двумя завихрителями (формирующим и стабилизирующим), двумя расширительными камерами и симметричной подачей ПОГ, позволяет произвести 
достаточно качественный раскрой листовой стали в условиях узкоструйной воздушноплазменной резки в довольно широком диапазоне толщин вплоть до 40 мм и более. Однако необходимо учитывать, что сварку заготовок без предварительной механической обработки можно производить при толщине реза 10 мм. При больших-толщинах в разделочном шве формируется ЗТВ со значительными изменениями в структуре основного металла и ряда других показателей, что предполагает снятие фаски с поверхности реза на глубину не менее 0,5 мм.

\section{Благодарность}

Работа выполнена при поддержке Госзадания Минобрнауки РФ на 2018-2019 г2. № 13.10317.2018/11.12 (Рег. № НИОКТР АААА-А18-118110790009-3)

\section{Литература}

1. Кайдалов А. А. Современные технологии термической и дистанционной резки конструкционных материалов. - Киев : Экотехнология, 2007. - 456 с.

2. Лащенко Г. И. Плазменная резка металлов и сплавов. - К. : Экотехнология, 2003. $64 \mathrm{c}$.

3. Коротеев А. С., Миронов В. М., Свирчук Ю. С. Плазмотроны. Конструкции, характеристики, расчет. - М. : Машиностроение, 1993. - 296 с.

4. Жуков М. Ф., Аньшаков А. С. Основы расчета плазмотронов линейной схемы. Новосибирск : Ин-т теплофизики СО АН СССР, 1979. - 146 с.

5. Донской А. В., Клубникин В. С. Электроплазменные процессы и установки в машиностроении. - Л. : Машиностроение, 1979. - 221 с.

6. Анахов С. В., Пыкин Ю. А. Плазмотроны: проблема акустической безопасности. Теплофизические и газодинамические принципы проектирования малошумных плазмотронов. - Екатеринбург : РИО УрО РАН, 2012. - 224 с.

7. Чиеу Куанг Фи. Исследование эффективности технологии узкоструйной плазменной резки металлов ... дис. канд. техн. наук. - С.-Петербург : С.- Пб. ГМТУ, 2008. - 143 с.

8. Оценка эффективности газовихревой стабилизации в плазмотронах для резки металлов / М. П. Шалимов, С. В. Анахов, Ю. А. Пыкин, А. В. Матушкин, И. Ю. Матушкина // Сварка и диагностика. - 2018. - № 2. - С. 57-61.

9. Анахов С. В. Принципы и методы проектирования плазмотронов. - Екатеринбург : Изд-во Рос. гос. проф.-пед. ун-та, 2018. - 165 с.

10. Анахов С. В., Пыкин Ю. А., Матушкин А. В. Повышение эффективности системы газовихревой стабилизации в плазмотронах для высокоточной резки металлов // Сварочное производство. - 2019. - № 4. - С. 27-30.

11. Влияние конструктивных особенностей плазмотрона на качество реза при прецизионной воздушно-плазменной разделке металла / С. В. Анахов, Б. Н. Гузанов, А. В. Матушкин, Н. Б. Пугачева, Ю. А. Пыкин // Известия высших учебных заведений. Черная металлургия. 2020. - T. 63, № 2. - C. 155-162. - DOI: 10.17073/0368-0797-2020-2-155-162.

12. ГОСТ 8233-56. Сталь. Эталоны микроструктуры. - Москва : ИПК Издательство стандартов, 2004. 